\section{Regards sur l'économie allemande}

Bulletin économique du CIRAC

113 | 2014

Varia

\title{
Karlsruhe : impôt sur les successions des PME
}

\section{Isabelle Bourgeois}

\section{OpenEdition \\ Journals}

Édition électronique

URL : https://journals.openedition.org/rea/4697

DOI : $10.4000 /$ rea. 4697

ISSN : 1965-0787

Éditeur

CIRAC

Édition imprimée

Date de publication : 15 juillet 2014

Pagination : 43-44

ISSN : 1156-8992

Référence électronique

Isabelle Bourgeois, "Karlsruhe : impôt sur les successions des PME ", Regards sur l'économie allemande [En ligne], 113 | juillet 2014, mis en ligne le 17 juillet 2016, consulté le 28 juin 2022. URL :

http://journals.openedition.org/rea/4697 ; DOI : https://doi.org/10.4000/rea.4697

Ce document a été généré automatiquement le 29 septembre 2020.

(c) CIRAC 


\title{
Karlsruhe : impôt sur les successions des PME
}

\author{
Isabelle Bourgeois
}

\section{Sur la sellette : les abattements pour les PME}

1 A l'automne, le Tribunal constitutionnel fédéral rendra un arrêt redouté par le Mittelstand allemand ( 1 BvL 21/12). Il doit décider en dernière instance de la constitutionnalité du régime particulier qui est réservé aux sociétés de personnes depuis l'entrée en vigueur, le 01-01-2009, de la Loi de réforme de l'impôt sur les successions (Erbschaftsteuerreformgesetz du 24 décembre 2008, ErbStG). La Cour fédérale de juridiction financière (Bundesfinanzhof) de Munich avait en effet saisi en septembre 2012 la Cour suprême d'un contrôle en constitutionnalité portant, entre autres, sur les $\S \S 13 \mathrm{a}$ et $13 \mathrm{~b}$ de cette loi qui règlent l'exonération partielle ou totale des sociétés de personnes de l'impôt sur les successions. Ils jugent que, même partielle et sous conditions, cette exonération "n'est pas suffisamment justifiée par l'intérêt général et constitue de ce fait un privilège indu contraire à la Loi fondamentale ", ainsi que le résume le communiqué de la Cour de Karlsruhe publié à l'occasion de son délibéré, le 8 juillet 2014. En effet, selon la Cour de Munich, rien ne permet d'affirmer que l'imposition des successions menacerait la pérennité des entreprises.

\section{Des abattements soumis à contrepartie}

2 Les dispositions en cause concernent la plupart des entreprises du Mittelstand, qui sont presque toutes des familiales ( $95 \%$ ) et des sociétés de personnes (près de $83 \%$ ). L'estimation des biens à transmettre s'effectue selon leur valeur vénale et un allégement fiscal n'est prévu que dans le cas où un membre de la famille reprend l'entreprise et respecte un certain nombre d'obligations destinées à préserver l'emploi. L'héritier bénéficie alors d'un abattement de $85 \%$ s'il conserve le patrimoine de l'entreprise pendant 5 ans et si, durant cette période, la masse salariale cumulée ne 
passe pas en-dessous de $400 \%$ de son niveau initial (cette obligation ne s'applique pas aux entreprises de moins de 20 salariés). Les $15 \%$ restants de la valeur de la société bénéficient d'un abattement plafonné à $150000 €$. Si l'héritier s'engage à conserver le patrimoine durant 7 ans et à respecter un seuil d'au moins $700 \%$ de la masse salariale cumulée, l'exonération est totale (100\%). Dans tous les cas, la valeur d'exploitation non indispensable à l'activité doit être inférieure à $50 \%$ du total.

\section{Des dispositions violant le principe d'égalité de traitement et faciles à contourner?}

La Cour fédérale de juridiction financière juge que ces dispositions, de même que le barème dégressif appliqué ( $\$ 19 \mathrm{ErbStG}$ ), violent le principe d'égalité de traitement (art. 3 de la Loi fondamentale). En effet, rappelle-t-elle, le seuil de la masse salariale n'est pas justifié, puisque plus de $90 \%$ de toutes les entreprises allemandes occupent moins de 20 salariés. Quant aux autres, elles peuvent aisément recourir à des subterfuges pour réduire leur effectif sur le papier, par exemple en scindant la société. Quant au seuil de $50 \%$ de la valeur d'exploitation non indispensable, il peut tout aussi aisément être contourné : il est pratique courante que les héritiers transfèrent une partie de leur patrimoine personnel à une société de capitaux ou une autre société de personnes pour la transformer ainsi en patrimoine de l'entreprise et la faire échapper à l'impôt. En d'autres termes, la Cour de Munich juge que ces dispositions font de l'exonération la règle, l'imposition devenant l'exception.

\section{Un manque à gagner de près de 11 milliards $€$ ?}

Quelques jours avant le délibéré de la Cour de Karlsruhe, le ministère fédéral des Finances a pour la première fois communiqué le volume global de ces exonérations. Il estime qu'en 2012 (derniers chiffres disponibles), 10,8 milliards $€$ ont ainsi échappé au fisc en toute légalité, l'encours de l'impôt sur les successions d'entreprises s'élevant à 4,3 milliards $€$. Sur les quatre années depuis l'entrée en vigueur de ces dispositions, le manque à gagner s'élèverait à quelque 19 milliards $€$.

\section{Cris d'orfraie du Mittelstand}

Le Mittelstand s'inquiète de voir la Cour de Karlsruhe déclarer anticonstitutionnel ce régime d'allégements. Et prépare sa défense, rappelant le rôle stratégique des PME innovantes et internationalisées pour l'économie allemande. Un des secrets de la pérennité des PME ou ETI allemandes ne réside-t-il pas justement dans cet avantage fiscal qui permet de réinvestir les bénéfices dans l'entreprise ? Et si les PME ne peuvent plus faire face à la pression fiscale, ne s'exposent-elles pas à une vague de rachat par des investisseurs étrangers? D'autres encore avancent la menace d'une vague d'expatriation... Les fédérations fourbissent leurs armes - de la Fédération des Entreprises familiales à celle de l'Industrie. Ironie du sort, elles défendent aujourd'hui bec et ongles des dispositions qu'elles rejetaient avec la même vigueur au moment de l'adoption de la loi de réforme (voir REA 92/2009). 


\section{Un dossier hautement complexe et à prolongements multiples}

Ce dossier prête à débat depuis longtemps, et il ne perdra rien de son caractère sensible dans un proche avenir. Car d'une part, il renvoie à l'ordonnancement de l'ensemble de la fiscalité des entreprises et des particuliers, du patrimoine comme du capital. Chaque réforme engagée sur un point précis déclenche un processus de réformes à tiroirs (voir REA 84/2007), ne serait-ce que parce que les sociétés de personnes sont soumises au régime de l'impôt sur le revenu en ce qui concerne leur propriétaire. Ce fait ne simplifie pas non plus le processus d'harmonisation européenne de l'impôt sur les sociétés. D'autre part, ce dossier s'inscrit dans la très épineuse révision en cours des modalités concrètes du fédéralisme financier: en effet, l'impôt sur les successions revient en propre aux Länder. Et dans la perspective de 2020, année où les Länder ne pourront plus recourir à l'endettement, comme de 2019, année où prend fin en théorie le soutien aux Länder est-allemands (Aufbau Ost), les Länder ne seraient pas hostiles à un possible complément de ressources fiscales. Karlsruhe n'a pas la partie facile : la Cour doit concilier égalité de traitement prévu dans la Constitution - entre sociétés de capitaux et sociétés de personnes, mais aussi entre PME et particuliers - et intérêt économique général. L'équilibre est particulièrement délicat à trouver en matière de fiscalité : la Cour fédérale de juridiction financière et le Tribunal constitutionnel fédéral se renvoient la balle sur cette question depuis bientôt dix ans. Comme toujours, c'est au législateur qu'il reviendra in fine de donner vie à cet équilibre entre normes de droit.

\section{INDEX}

Mots-clés : impôt, impôt sur les successions, PME, Mittelstand 